\title{
Glicogenose hereditária em bovinos Brahman no Brasil ${ }^{1}$
}

\author{
P. Zlotowski², L. Nakazato ${ }^{3}$, V. Dutra ${ }^{3}$, S.S. Barros ${ }^{4}$, E.J. Gimeno ${ }^{5}$, M. Göcks ${ }^{6}$, E.M. \\ Colodel $^{3}$ e D. Driemeier ${ }^{2}$
}

\begin{abstract}
Zlotowski P., Nakazato L., Dutra V., Barros S. S., Gimeno E.J., Göcks M., Colodel E. M. \& Driemeier D. 2005. [Inherited glycogenosis in Brahman cattle in Brazil.] Glicogenose hereditária em bovinos Brahman no Brasil. Pesquisa Veterinária Brasileira 25(4):210-214. Setor de Patologia Veterinária, Departamento de Patologia Clínica Veterinária, Faculdade de Veterinária, Universidade Federal do Rio Grande do Sul, Av. Bento Gonçalves 9090, Bairro Agronomia, Cx. Postal 15094, Porto Alegre, RS 91540-000. Brazil. E-mail: davetpat@ufrgs.br

An inherited disease of cattle, characterized by lysosomal storage of glycogen in several tissues, is reported. The disease was diagnosed in a Brahman herd in the municipality of Porto Lucena, Rio Grande do Sul, Brazil. Affected calves, after one month of age, showed progressive difficulty to follow their mother, retarded growth, muscular weakness and tremors, lethargy and poor body condition. All affected calves were sired by the same bull. Necropsy was performed on three affected calves. The only gross lesion detected was paleness of the skeletal muscles of the trunk and limbs. Cytoplasmic vacuoles, the main histological lesion, were particularly evident in skeletal muscles, myocardium and Purkinje fibers, in neurons of the brain and spinal cord. Large amounts of periodic acid Schiff (PAS) positive granules were also observed in these most severely affected tissues. Pretreatment with diastase completely abolished the PAS reactivity. The 1057?TA, a lethal mutation in the gene of the acid alpha-glucosidase, which causes generalized glycogenosis in Brahman cattle, was detected by PCR in paraffin embedded tissues of affected animals on which post-mortem examination was performed. Clinical, histological and molecular findings were similar to previous descriptions of generalized glycogenosis in Brahman cattle in Australia. No previous indexed reports about generalized glycogenosis of Brahman cattle in Brazil could be found.
\end{abstract}

INDEX TERMS: Glycogenosis, inherited disease, Brahman cattle.

RESUMO.- Relata-se uma enfermidade hereditária em bovinos caracterizada por acúmulo lisossomal de glicogênio em diversos órgãos. A doença foi diagnosticada em um rebanho da raça Brahman, no município de Porto Lucena, Rio Grande do Sul,

\footnotetext{
${ }^{1}$ Recebido em 20 de junho de 2005.

Aceito para publicação em 8 de julho de 2005 .

Parte da dissertação de mestrado do primeiro autor, Pós-Graduação em Patologia Veterinária, Universidade Federal do Rio Grande do Sul (UFRGS).

2 Setor de Patologia Veterinária, Depto Patologia Clínica Veterinária, Faculdade de Veterinária, UFRGS, Cx. Postal 15094, Porto Alegre, RS 91540000. Autor para correspondência. E-mail: davetpat@ufrgs.br

${ }^{3}$ Departamento de Clínica Médica Veterinária, Universidade Federal do Mato Grosso, Brasil, Av Fernando Corrêa da Costa s/n, CEP: 78060-900, Cuiabá, MT.

${ }^{4}$ Pesquisador Visitante, Depto Patologia, Faculdade de Veterinária, Universidade Federal de Pelotas, Pelotas, RS 96010-900.

${ }^{5}$ Instituto de Patologia, Faculdade de Ciências Veterinárias, Universidade Nacional de La Plata, P.O. Box 296, 1900 La Plata, Argentina.

${ }^{6}$ Médico Veterinário autônomo, Rua do Comércio, 1871/401, Centro, Ijuí, RS 98700-000.
}

Brasil. Os animais afetados, a partir de 1 mês de idade, apresentavam dificuldade em acompanhar a mãe e crescimento retardado, desenvolviam fraqueza e tremores musculares, letargia e perda de condição corporal progressivos. Todos os bezerros eram descendentes do mesmo touro. Foi realizada necropsia em três bezerros doentes; palidez muscular do tronco e membros foi a única alteração macroscópica encontrada. Vacuolização citoplasmática de diversos órgãos foi a principal alteração histológica observada. Os vacúolos citoplasmáticos eram mais evidentes na musculatura esquelética, miocárdio, especialmente nas fibras de Purkinje e em neurônios do Sistema Nervoso Central (SNC). Nos tecidos mais afetados foi observada grande quantidade de grânulos ácido periódico de Schiff(PAS), positivos e negativos quando o tecido era tratado previamente com diastase. Uma mutação no gene da glicosidase alfa ácida, causadora da glicogenose generalizada em bovinos Brahman, a 1057?TA, foi detectada pela técnica de reação em cadeia de polimerase (PCR) em tecidos dos animais necropsiados. Também foi detectada a presença dessa mutação em amostras de sangue de animais parentes dos bezerros doentes. Os achados clínicos, 
patológicos e moleculares são semelhante ás descrições de glicogenose tipo II em bovinos da raça Brahman descritos na Austrália. Não foram encontrados relatos anteriores em revistas indexadas sobre glicogenose hereditária em bovinos Brahman no Brasil.

TERMOS DE INDEXAÇÃO: Glicogenose hereditária, bovinos Brahman.

\section{INTRODUÇÃO}

Glicogenose tipo II ou doença de Pompe é uma doença autossômica recessiva que foi descrita em humanos, bovinos das raças Shorthorn (Edwards \& Richards 1979) e Brahman (O'Sullivan et al. 1981), cães da raça Lapland (Walvoort 1985), gato (Sandstrom et al. 1969), ovelha (Manktelow \& Hartley 1975) e codorna japonesa (Matsui et al. 1983). Esta doença é determinada por mutação no gene da glicosidase alfa ácida, o que impede parte ou toda a biossíntese da enzima e, conseqüientemente, a degradação lisossomal de glicogênio (Bijvoet et al. 1998). Em decorrência há acúmulo de glicogênio nos lisossomos das células de diversos órgãos. (Wisselar et al. 1993).

Os sinais clínicos, percebidos em bezerros ao redor dos 2 a 3 meses de idade, se caracterizam por perda de condição corporal, crescimento retardado, se comparado aos animais da mesma idade, letargia e incoordenação. Após o desmame há uma piora rápida dos sinais clínicos. A incoordenação torna-se mais pronunciada, aparecem tremores musculares e, quando excitados, os animais caem, permanecendo na mesma posição por algum tempo e apresentando dificuldade em se levantar. A maioria dos bezerros é sacrificada ou morre de causas acidentais com cerca de 9 meses de vida (O'Sullivan et al. 1981).

Não são encontradas lesões macroscópicas significativas em animais com glicogenose tipo II (O'Sullivan et al. 1981), no entanto, pode haver, em alguns casos, palidez da musculatura esquelética (Reichmann et al. 1993).

O exame histológico revela vacuolização do citoplasma celular em diversos tecidos. As fibras de Purkinje do coração apresentam-se tumefeitas e vacuolizadas, contendo grande quantidade de material ácido periódico de Schiff(PAS) positivo, o qual é digerido com tratamento prévio pela diastase. Fibras do miocárdio e da musculatura esquelética são marcadamente vacuolizadas. As lesões mais acentuadas no sistema nervoso central (SNC) são representadas por vacuolização do citoplasma de neurônios. Observam-se também vacúolos em hepatócitos, epitélio tubular renal, epitélio glandular da tireóide, musculatura lisa dos intestinos, rúmen e abomaso e em células ganglionares da retina $\left(0^{\prime}\right.$ Sullivan et al. 1981).

Por ação de um alcalóide indolizidínico, o consumo de sementes de Castanospermum australe também pode causar a inibição da enzima glicosidase alfa ácida, a mesma responsável pela glicogenose dos bovinos da raça Brahman de origem genética (Reichmann et al. 1993). No entanto, em estudos realizados por Reichmann et al. (1989), não foram observados vacuolização ou acúmulo de glicogênio na análise histopatológica de tecidos de animais que receberam sementes de $C$. australe.

Recentemente, testes de PCR têm sido desenvolvidos na genotipagem de bovinos da raça Brahman para os três alelos com perda de função no gene da glicosidase alfa ácida. A utiliza- ção deste ensaio de PCR, baseado em restrição enzimática, facilita a seleção precisa contra os alelos 1057DTA e 1783T, e, conseqüentemente, reduz a prevalência de glicogenose em rebanhos registrados e comerciais de Brahman (Dennis et al. 2002).

A demonstração bioquímica da deficiência da glicosidase alfa ácida e/ou a evidência histológica de tecidos vacuolizados contendo glicogênio, corado pelo PAS, fornece um diagnóstico definitivo de glicogenose generalizada na maioria dos casos analisados (Reichmann et al. 1993).

Não há tratamento específico para esta doença em animais. A presença da glicogenose em um rebanho bovino pode causar grande perda econômica para o produtor (Dennis et al. 2002). É de fundamental importância que em propriedades onde haja animais clinicamente afetados por esta doença sejam identificados e retirados dos serviços de reprodução os animais heterozigotos recessivos (Healy et al. 1987).

Glicogenose hereditária em bovinos da raça Brahman tem sido amplamente descrita na Austrália (O'Sullivan et al. 1981, Reichmann et al. 1993, Dennis et al. 2002). No Brasil, em literatura indexada, não há casos descritos de glicogenose hereditária em bovinos. $\mathrm{O}$ objetivo do presente trabalho foi descrever os aspectos epidemiológicos, clínicos, patológicos e moleculares da glicogenose hereditária que ocorrem em bovinos da raça Brahman no município de Porto Lucena, Rio Grande do Sul nos anos de 2000, 2001 e 2002.

\section{MATERIAL E MÉTODOS}

Sinais clínicos e dados epidemiológicos foram coletados junto ao proprietário e ao médico veterinário responsável em visitas realizadas a propriedade. Foram necropsiados três bezerros doentes, dois machos, um com 1 ano de idade e outro com 9 meses, e uma fêmea de 6 meses de idade. Fragmentos de diversos órgãos foram coletados e fixados em formol tamponado a $10 \%$ e processados rotineiramente para a histopatologia. Coloração pelo PAS com e sem tratamento prévio pela diastase foi realizada em cortes histológicos e em esfregaços sangüíneos dos animais afetados (Prophet at al. 1992).

Para a identificação dos genes responsáveis pela glicogenose generalizada tipo $2 \mathrm{em}$ bovinos da raça Brahman, foram obtidos cortes de 20 micra em micrótomo manual, de amostras do SNC, emblocadas em parafina, pré fixadas em formol à $10 \%$ (Coombs et al. 1999, Shi et al. 2002). A técnica de PCR foi processada no departamento de Biotecnologia da UFRGS, segundo o descrito por Dennis et al. (2000).

Amostras de sangue de duas bezerras, filhas do touro pai dos bezerros doentes, e de três vacas que pariram bezerros doentes (Quadro 1) foram coletadas, com a finalidade de identificar a presença de animais heterozigotos presentes no rebanho através da técnica de PCR (Miller et al. 1988).

Quadro 1. Identificação dos bovinos dos quais foi coletado sangue para detecção de heterozigotos

\begin{tabular}{cc}
\hline $\begin{array}{c}\text { Identificação } \\
\text { dos animais }\end{array}$ & $\begin{array}{c}\text { Parentesco com os animais envolvidos } \\
\text { com os casos da doença no rebanho }\end{array}$ \\
\hline 1 & Filha do touro Brahman \\
2 & Mãe de um bezerro doente \\
3 & Mãe de um bezerro doente \\
4 & Filha do touro Brahman \\
5 & Mãe de dois bezerros doentes
\end{tabular}




\section{RESULTADOS}

A propriedade onde ocorreu o nascimento dos animais doentes situa-se em Porto Lucena, Rio Grande do Sul. O rebanho era composto por um touro da raça Brahman e 20 vacas cruza Brahman, criados de forma extensiva em pasto nativo. No Quadro 2 é apresentado o total de animais nascidos na propriedade e o número de animais com sinais clínicos, nos três anos de ocorrência da enfermidade. No ano de 2002 o touro foi descartado do rebanho e um touro da raça Nelore foi utilizado para reprodução. Em 2003, após a introdução do novo touro, não foi observado o nascimento de animais doentes.

Os sinais clínicos iniciavam nos animais ao redor de 1 mês de

Quadro 2. Total de bovinos nascidos e total de afetados no período de ocorrência da enfermidade

\begin{tabular}{cccc}
\hline Ano & Total de nascimentos & Animais afetados & $\%$ \\
\hline 2000 & 16 & 3 & 18,75 \\
2001 & 19 & 5 & 26,3 \\
2002 & 12 & 2 & 16,6 \\
Total & 47 & 10 & 21
\end{tabular}

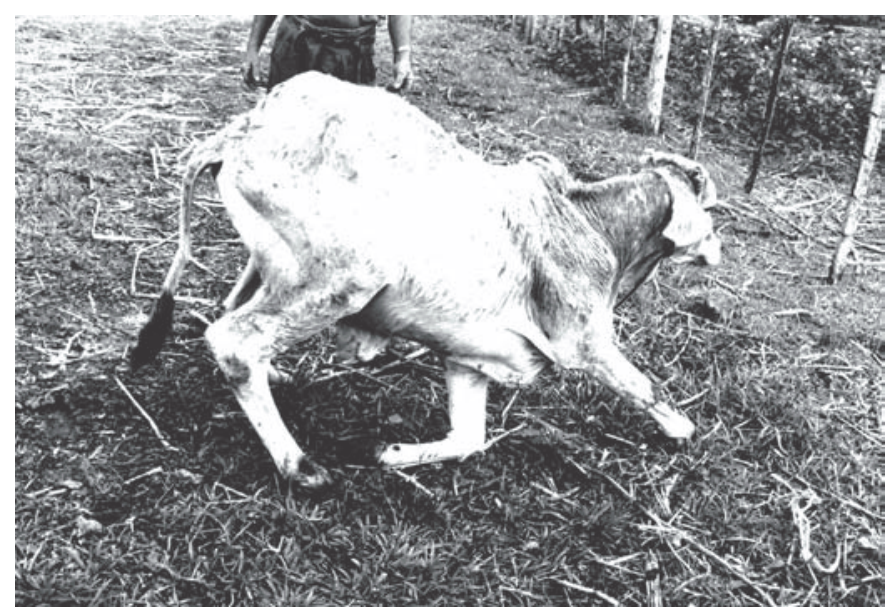

Fig.1. Bovino cruza Brahman com glicogenose generalizada apresentando fraqueza muscular.

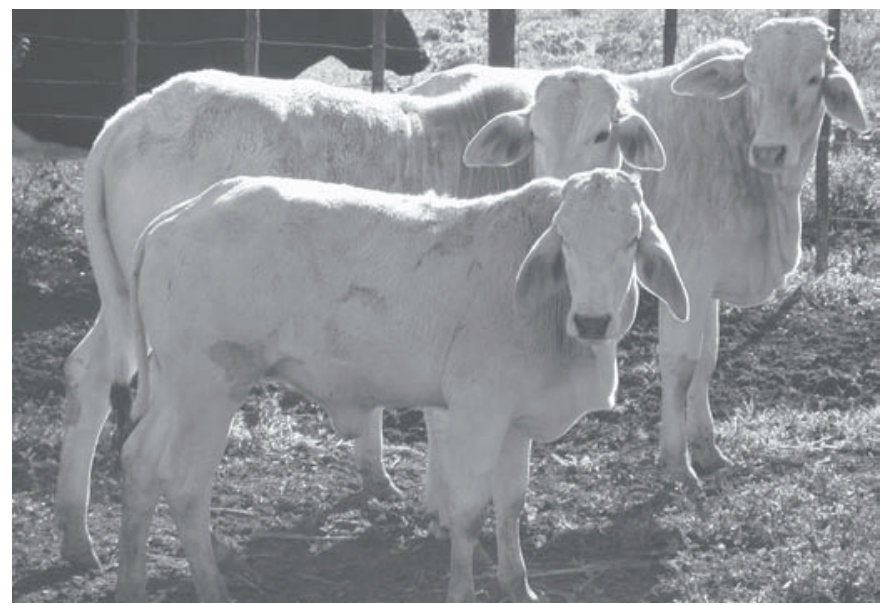

Fig.2. Bovino cruza Brahman com glicogenose generalizada, com apatia e menor desenvolvimento em relação a bovinos normais da mesma idade.

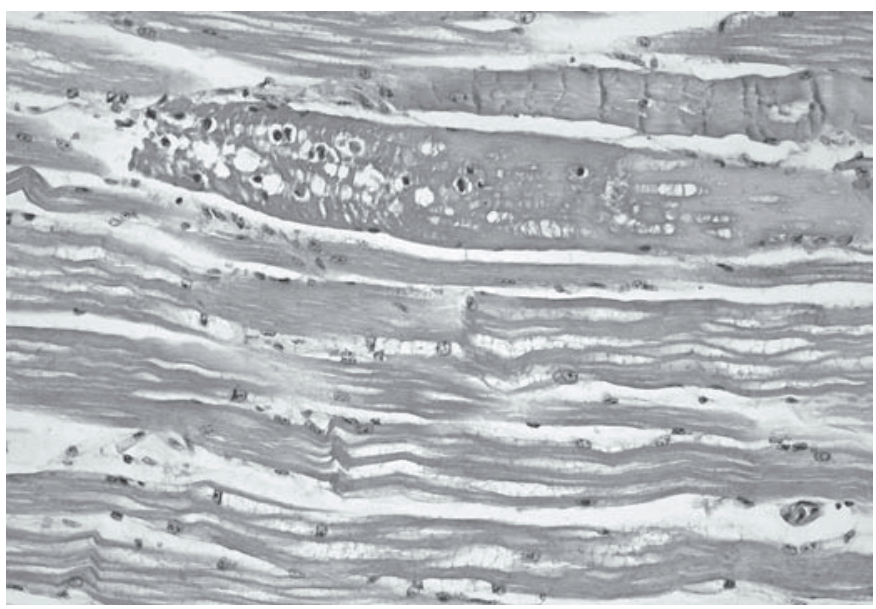

Fig.3. Vacuolização acentuada da musculatura esquelética com necrose de fibra muscular associada a infiltrado mononuclear. HE, obj. 40.

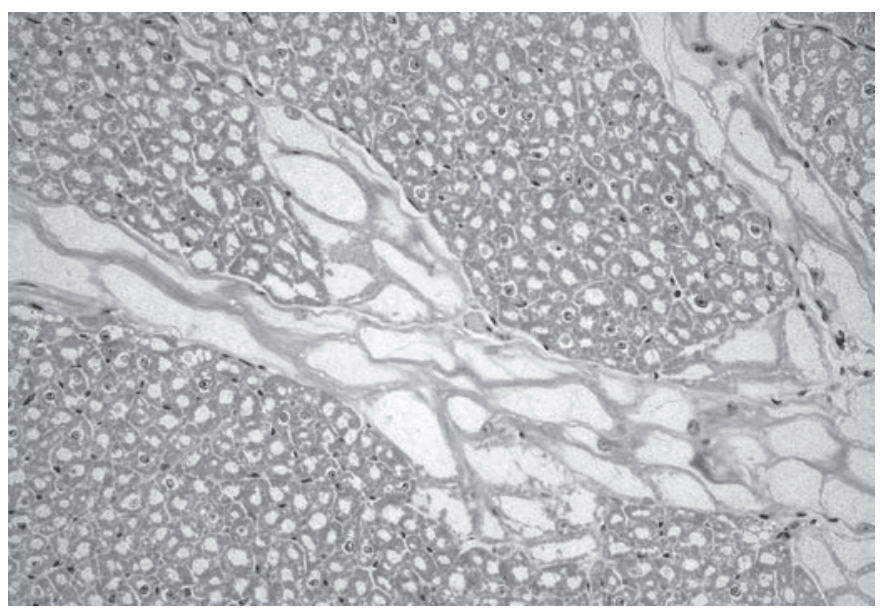

Fig.4. Vacuolização acentuada das fibras de Purkinje e da musculatura cardíaca. HE, obj. 20.

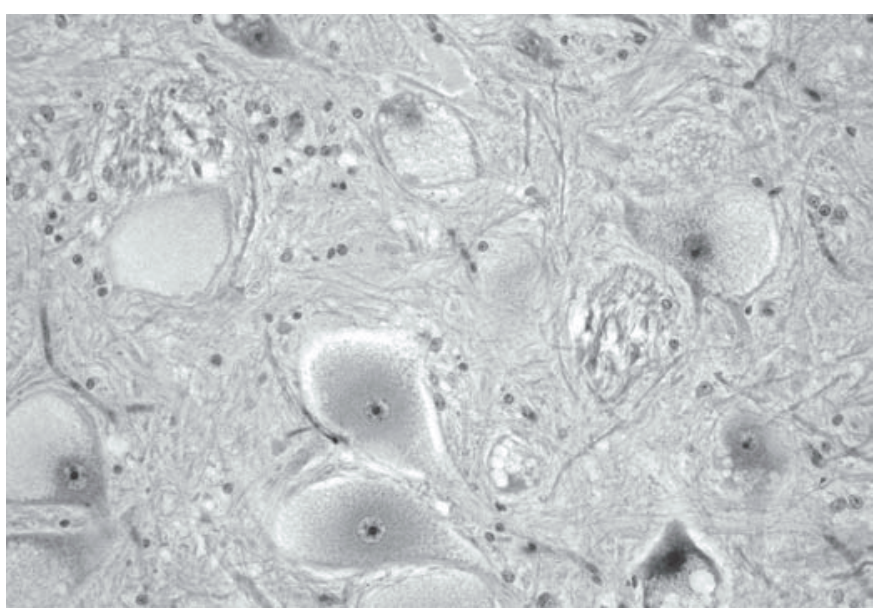

Fig.5. Neurônios do mesencéfalo com vacuolização e distensão do citoplasma. HE, obj. 20.

idade e progrediam com a idade. Eram administrados antibióticos, anti-helmínticos e fluidoterapia aos animais doentes, sem melhora clínica. Foi realizada eutanásia nestes animais devido a incapacidade de se alimentarem ou beber água sem auxílio. 
Em visita realizada à propriedade não foram encontradas plantas tóxicas que pudessem causar sintomatologia clínica e lesões histopatológicas semelhantes às verificadas em animais enfermos.

Os animais apresentavam fraqueza, tremores musculares, letargia, apatia, dificuldade em acompanhar a mãe, quedas constantes (Fig.1) com incapacidade de voltar à estação e retardo no crescimento (Fig.2).

Palidez moderada da musculatura dos membros e tronco foi a única alteração macroscópica encontrada nos três animais necropsiados.

Vacuolização e distensão citoplasmática em células de diversos tecidos foram as principais alterações histológicas encontradas. Estas alterações eram mais acentuadas e evidentes na musculatura esquelética (Fig.3), miocárdio e fibras de Purkinje do coração (Fig. 4). Nas fibras musculares esqueléticas observaramse áreas multifocais de necrose associada a infiltrado histiocítico moderado (Fig.3).

No SNC, vacuolização do citoplasma neuronal foi a principal lesão histológica encontrada, sendo mais severa na região do óbex, substância branca e camada granular do cerebelo, mesencéfalo (Fig.5) e medula espinhal. Na região cerebelar, neurônios de Golgi da camada granular mostraram-se intensamente vacuolizados, enquanto que em neurônios de Purkinje apresentavam somente leve vacuolização. Na medula espinhal foi observada acentuada vacuolização em neurônios das raízes dorsal e ventral, sem diferenças significativas nestas áreas. Havia, também, vacuolização em neurônios dos plexos mioentérico e submucoso do intestino e do gânglio trigêmio.

Na pele foi encontrada intensa vacuolização dos músculos pilo-eretores e na túnica muscular de vasos. Vacúolos foram também observados no epitélio glandular da tireóide, epitélio tubular renal, musculatura lisa dos intestinos e do rúmen, células ganglionares da retina e em hepatócitos. Na análise histológica do epidídimo de um dos animais verificou-se vacuolização das células epiteliais, mais intensa na região do corpo do epidídimo.

No esfregaço de sangue dos animais necropsiados observou-se vacuolização em monócitos, com material PAS positivo.

Os três animais analisados, com lesões características de glicogenose generalizada na microscopia óptica, foram positivos para a mutação 1057DTA no gene da glicosidase alfa ácida, clivados pela enzima de restrição Bgl I, com padrão de homozigose. Foi detectada heterozigose para mutação 1057DTA na análise do sangue dos Bovinos 1, 2, 3 e 5, que eram clinicamente normais. $\mathrm{O}$ Bovino 4 revelou-se homozigoto selvagem do alelo 1057. Todos os animais testados foram homozigotos para os alelos 1783 e 1351 .

\section{DISCUSSÃO}

Os achados clínicos, histológicos e moleculares observados nesses bezerros Brahman são consistentes com relatos anteriores de glicogenose generalizada tipo II em bovinos da raça Brahman na Austrália (0’Sullivan et al. 1981, Reichmann et al. 1993). O diagnóstico de glicogenose generalizada foi confirmado pela presença da mutação letal 1057?TA no gene da glicosidase alfa ácida nos tecidos dos bezerros doentes. Esta mutação ocorre somente em bovinos da raça Brahman e é a mais comum relaci- onada com glicogenose generalizada nesta raça (Dennis et al. 2002).

Algumas características presentes em doenças do acúmulo lisossomal foram encontradas no rebanho afetado, e contribuíram para o diagnóstico presuntivo da doença. Entre elas o caráter hereditário autossômico recessivo, com o nascimento de bezerros doentes do cruzamento de pais heterozigotos clinicamente normais e a ocorrência em uma raça específica, na qual uma doença do acúmulo lisossomal foi relatada (Summers et al. 1995).

A introdução de um novo touro da raça Nelore para cobertura das vacas Brahman sugere que o touro Brahman que estava sendo utilizado para reprodução era heterozigoto para a mutação 1057DTA, já que não foram relatados casos da doença com a utilização do novo touro. As vacas eram as mesmas que tinham parido bezerros doentes, mas o cruzamento com um touro nãoportador do gene não permitiu a ocorrência de homozigose e o nascimento de animais doentes. A mutação 1057DTA no gene da glicosidase alfa ácida encontrada nos filhos do touro Brahman reforçam a possibilidade deste animal ser heterozigoto para a mutação em questão. Os alelos 1783C e 1351C em homozigose confirmam o envolvimento da mutação 1057DTA nos casos analisados. A amostra identificada como 4, proveniente de uma filha do touro Brahman apresentou o alelo 1057 selvagem, indicando que esta vaca não é portadora de genes causadores de glicogenose generalizada, de forma que pode ser utilizada para reprodução sem haver transmissão dos genes da doença para a progênie.

O principal sinal clínico da doença, caracterizado por fraqueza muscular está relacionado com os achados microscópicos de vacuolização acentuada na musculatura esquelética com presença de material PAS positivo. A progressão desse sinal clínico é devida à evolução da lesão muscular, que parece aumentar com a idade. $O$ dano da fibra muscular é progressivo e responsável pela fraqueza muscular, falha cardíaca e respiratória terminal (McC.Howell et al. 1984). Acredita-se que o conteúdo lisossomal, liberado no sarcoplasma, cause necrose de fibras musculares nos animais doentes. Tal evento é sugerido pelo constante e elevado conteúdo de glicogênio no músculo afetado, que não pode ser degradado nos lisossomos devido à falta de atividade hidrolítica disponível (McC.Howell et al. 1984). A análise do SNC dos animais afetados não demonstrou diferenças significativas na intensidade das lesões. Apesar do dano na musculatura esquelética, causado pelo acúmulo de glicogênio, ser progressivo, aumentando com a idade, este comportamento não tem sido observado no tecido nervoso de bovinos com glicogenose generalizada. Cook et al. (1982) avaliaram o SNC de dois bezerros de 3 e 7 meses de idade e de um outro animal que morreu com 1 ano de idade, as lesões encontradas no tecido nervoso eram semelhantes.

Apesar da intensidade das lesões encontradas no SNC, não foram observados sinais clínicos significativos associados nos bovinos estudados. A leve vacuolização citoplasmática observada nos neurônios de Purkinje, com discreta presença de grânulos de glicogênio cercados por membrana, encontrados nos animais doentes, foram anteriormente descritas em bovinos da raça Shorthorn (Edwards \& Richards 1979); neste estudo, ao 
exame clínico do sistema nervoso, os animais se mostraram alerta, com percepção de dor normal, resposta à ameaça e reflexo pupilar. Não houve evidências de movimentos de cabeça, estrabismo ou nistagmo, indicando que o efeito de glicogenose generalizada na função neurológica é limitado.

As áreas do córtex cerebral responsáveis pelo comportamento, intelecto e traços de personalidade são o lobo frontal e córtex temporal. Os estados mentais de depressão podem ser decorrentes de alterações nestas áreas juntamente com o sistema límbico. A apatia apresentada pelos animais doentes pode ser uma manifestação neurológica da doença decorrente da lesão no córtex cerebral e/ou áreas correspondentes ao sistema límbico.

Atualmente, o rebanho brasileiro é composto de aproximadamente sete mil animais puros com estimativas de alcançar $20 \mathrm{mi}-$ lhões de cabeças com sangue Brahman em 10 ou 15 anos. Como raça zebuína, o Brahman apresenta maior rusticidade e adaptação às regiões de clima quente, assim como o Nelore, raça de corte predominante no país. Maior precocidade sexual e de terminação e carcaça superior, podem gerar produtos com mais arroubas ao desmame são características da raça Brahman que a tornam importante economicamente para cruza com gado Nelore, resultando em animais adaptados, mais aptos para produção de carne e com maior precocidade (Toledo 2004). A possibilidade de expansão desta raça no país faz com que medidas de controle sejam tomadas para impedir a ocorrência de glicogenose e evitar as perdas econômicas decorrentes. Estas medidas de controle devem incluir a testagem de animais e sêmen adquiridos de outros países, principalmente porque estes últimos representam uma forma rápida de disseminação da doença.

Não haviam sido relatados casos anteriores de glicogenose generalizada tipo II em bovinos da raça Brahman no Brasil. Esta doença deve ser levada em consideração no diagnóstico diferencial de outras doenças que cursem com fraqueza muscular em bovinos da raça Brahman e suas cruzas.

Agradecimentos.- Às laboratoristas do Setor de Patologia Veterinária da Universidade Federal do Rio Grande do Sul, Ângela R. B. de Souza e Marília T. Belmonte.

\section{REFERÊNCIAS}

Bijovet A.G.A., Van de Camp E.H.M., Kross M.A., Ding J.H., Yang B.Z., Visser P., Bakker C.E., Verbeet M.Ph., Oostra B.A., Reuser A.J.J. \& Vand der Ploeg A.T. 1998. Generalized glycogen storage and cardiomegaly in a knockout mouse model of Pompe disease. Hum. Mol.Genet. 8(1):53-62.

Coombs N.J., Gough A.C. \& Primrose J. N. 1999. Optimisation of DNA and
RNA extraction from archival formalin-fixed tissue. Nucleic Acids Res. 27(16):1-3.

Cook R.D., Howell M.C.C., Dorling P.R. \& Richards R.B. 1982. Changes in nervous tissue in bovine generalized glycogenosis type II. Neuropath. Appl. Neurobiol. 8:95-107.

Dennis J.A., Moran C., Healy P.J. 2000. The bovine a-glucosidase gene: coding region, genomic structure and mutation that cause bovine generalized glycogenosis. Mamm. Genome. 11:206-212.

Dennis J.A., Healy P.J. \& Reichmann K.G. 2002. Genotyping Brahman cattle for generalised glycogenosis. Aust. Vet. J. 80(5):286-291.

Edwards J.R. \& Richards R.B. 1979. Bovine generalized glycogenosis type II: a clinico-pathological study. Brit. Vet. J. 135(4):338-348.

Healy P.J., Sewell C.A., Nieper R.E., Whittle R.J. \& Reichmann K.G. 1987. Control of generalised glycogenosis in a Brahman herd. Aust. Vet. J. 64(9):278-280.

Manktelow B.W. \& Hartley W.J. 1975. Generalized glycogen storage disease in sheep. J. Comp. Pathol. 85:139-145.

Matsui T., Kuroda S., Mizutani M., Kiuchi Y., Suzuki K. \& Ono T. 1983. Generalized Glycogen Storage Disease in Japanese Quail (Coturnix coturnix japonica). Vet. Pathol. 20:312-321.

McC.Howell J., Dorling P.R. \& Cook R.D. 1984. The effect of age on biochemical and morphological changes in the semitendinosus muscle of cattle with generalized glycogenosis type II. Neuropathol. Appl. Neurobiol. 10:255-266.

O'Sullivan B.M., Healy P.J, Fraser I.R., Nieper R.E, Whittle R.J. \& Sewell C.A. 1981. Generalised glycogenosis in Brahman cattle. Aust.Vet. J. 57(5):227229.

Prophet E.B., Mills B., Arrington J.B. \& Sobin L.H. 1992. Laboratory methods in histotechnology. Armed Forces Institute of Pathology, American Registry of Pathology, Washington. 279p.

Reichmann K.G., Twist J.O., Mckenzie R.A. \& Rowan K.J. 1989. Inhibition of bovine á-glucosidase by Castanospermum australe: an attempted phenocopy of Pompe's disease. Aust. Vet. J. 64(9):274-276.

Reichmann K.G., Twist J.O. \& Thistlethwaite E.J. 1993. Clinical, diagnostic and biochemical features of generalised glycogenosis type II in Brahman cattle. Aust.Vet. J. 70(11):405-408.

Sandstrom B., Westman J. \& Ockerman P.A. 1969. Glycogenosis of the central nervous system in the cat. Acta Neuropathol. 14(3):194-200.

Shi S.R., Cote R.J., Wu L., Liu C., Datar R., Shi Y., Liu D., Lim H. \& Taylor C.R. 2002. DNA extraction from Archival formalin-fixed, paraffin-embedded tissue sections based on the antigen retrieval principle: heating under the influence of pH. J. Histochem. Cytochem. 50(8):1005-1011.

Toledo L.R. 2004. Zebu Americano. Globo Rural 19(222):28-34.

Walvoort H.C. 1985. Glycogen storage disease type II in the Lapland dog. Vet. Quarterly 7(3):187-190.

Wisselar H.A., Hermans M.M.P., Visser W.J., Kroos M.A., Oostra B.A., Aspden W., Harrison B., Hetzel D.J.S, Reuser A.J.J. \& Drinkwater R.D. 1993. Biochemical genetics of glycogenosis type II in Brahman cattle. Bioch. Bioph. Res. Comm. 190(3):941-947. 